\title{
ANALISIS KARAKTERISTIK KONSUMEN YANG BERBELANJA SEMBILAN BAHAN POKOK (SEMBAKO) DI PASAR TRADISIONAL DAN PASAR MODEREN DI KECAMATAN MARPOYAN DAMAI KOTA PEKANBARU
}

\author{
Chezy WM. Vermila \\ Email : chezyvermila@yahoo.com
}

\begin{abstract}
ABSTRAK
Penelitian ini bertujuan mengetahui karakteristik konsumen yang berbelanja kebutuhan sembilan bahan pokok (sembako) di pasar tradisional dan pasar modern di Kecamatan Marpoyan Damai. Penelitian ini dilaksanakan di Kelurahan Maharatu Kecamatan Marpoyan Damai Kota Pekanbaru.Sampel yang diambil sebanyak 120 orang dimana 80 konsumen yang memilih pasar tradisional dan 40 yang memilih pasar moderen. Metode penelitian yang digunakan adalah accidental sampling. Pengumpulan data dilakukan dengan wawancara. Pengumpulan data dilakukan dengan wawancara. Analisis yang digunakan dalam penelitian adalah analisis deskriptif. Karakteristik konsumen yaitu usia konsumen yang memilih pasar tradisional $31-40$ tahun dengan persentase $48.75 \%$, konsumen yang memilih pasar moderen 21 - 30 dengan persentase 55 persen. Jenis kelamin rata-rata jumlah konsumen untuk pasar tradisional sebanyak 54 konsumen atau $67.5 \%$, pasar moderen yaitu sebanyak 31 konsumen atau $77.5 \%$, suku yang lebih banyak suku melayu sebanyak 33 konsumen atau $41.25 \%$, pasar moderen 17 konsumen atau $42.5 \%$ tingkat pendidikan yang dominan untuk pasar tradisional yaitu SLTA sebanyak 38 konsumen atau $47.5 \%$, pasar moderen yaitu rata-rata diploma yaitu sebanyak 13 konsumen, Jenis pekerjaan adalah ibu rumah tangga baik pada pasar tradisional ataupun pasar moderen sebanyak 27 konsumen memilih pasar tradisonal dan 21 pasar moderen dengan persentase masing-masing $33.75 \%$ dan $52.5 \%$, Tingkat pendapatan konsumen adalah 1.500.0002.999.000,- mendominasi dipasar tradisional yaitu sebanyak 29 konsumen atau $35.25 \%$ pasar moderen dengan pendapatan 3.000.000 - 4.999.000 sebanyak 19 konsumen atau $47.5 \%$.
\end{abstract}

\section{Keywords : Analisis Karakteristik Konsumen, Konsumen, Beras.}

\section{PENDAHULUAN}

Sembako adalah singkatan dari sembilan bahan pokok yang terdiri atas berbagai bahan-bahan makanan dan minuman yang secara umum sangat dibutuhkan masyarakat Indonesia. Tanpa sembako kehidupan rakyat Indonesia bisa terganggu karena sembako merupakan kebutuhan pokok utama sehari-hari yang wajib ada dijual bebas di pasar.

Dibawah ini adalah daftar nama anggota bahan pokok sembako sesuai dengan keputusan meteri Industri Perdagangan no.115/mpp/kep/1998 tanggal 27 Februari 1998, yaitu antara lain : 1) Beras dan Sagu, 2) Jagung, 3) Sayur-sayuran 
dan Buah-buahan, 4) Daging baik sapi ataupun ayam, 5) Susu, 6) Gula Pasir, 7) Garam yang mengandung Yodium, 8) Minyak Goreng, 9) Minyak Tanah atau Gas Elpiji .

Dari sisi ekonomi permintaan barang-barang sembako bersifat inelastis, yaitu perubahan harga sembako tidak akan banyak mempengaruhi tingkat permintaan produk oleh konsumen selama tidak terlalu signifikan. Maka sebagian konsumen akan beralih ke produk serupa sebagai pengganti atau subsitusi (Anonim, 2013).

Kegiatan bisnis pada hakikatnya merupakan kegiatan yang berusaha untuk memenuhi kebutuhan masyarakat. Kita semua mengetahui bahwa masyarakat akan selalu memiliki berbagai kebutuhan yaitu mulai dari kebutuhan sehari-hari yang berupa makanan, minuman, dan pakaian serta papan atau perumahan bagi mereka, yang semua itu dikenal sebagai kebutuhan pokok atau kebutuhan primer (Gitosudarmo, 2001).

Menurut cara pandang Ilmu Ekonomi, pasar diidentifikasikan sebagai permintaan, yaitu jumlah produk yang dapat diserap oleh konsumen dari produk yang ditawarkan pada harga tertentu. Dalam hal ini konsumen berperan besar dalam menentukan jumlah produksi atau penawaran melalui pengeluaran yang mereka lakukan terhadap produk itu. Hal ini tercermin dalam pengaruh harga terhadap jumlah penawaran serta permintaan. Dilain pihak, dari sudut pandang bisnis pasar adalah tidak hanya interaksi antara penawaran dan permintaan saja akan tetapi merupakan orang-orang atau organisasi yang membutuhkan produk itu dan selanjutnya menyangkut siapa orang atau organisasi yang menbutuhkan produk tersebut serta bagaiman sifat-sifat mereka. Yang ditawarkan oleh pelaku bisnis tersebut. Jadi pelaku bisnis dalam hal ini lebih menitik beratkan dalam potensi pasar atau potensi bisnis dari pada konsumen pada saat ini saja beserta sifat-sifat yang dimiliki oleh potensi pasar tersebut. Dalam hal ini pasar atau potensi bisnis merupakan fungsi dari struktur penduduk (population patern), kemampuan membeli (purchasing power) dan pola konsumsi (consumtion patern). Hal ini dapat dilihat pada gambar dibawah ini. ( Indriyo Gitosudarmo, 2001).

Setiap konsumen akan membelanjakan atau mengalokasikan pendapatannya untuk dibelikan barang-barang konsumsi dan jasa-jasa konsumsi

93 Analisis Karakteristik Konsumen Yang Berbelanja Sembilan Bahan Pokok (Sembako) Di Pasar Tradisional Dan Pasar Moderen Di Kecamatan Marpoyan Damai Kota Pekanbaru 
untuk memenuhi kebutuhannya. Teori kepuasan konsumen akan membahas apa reaksi konsumen dalam kesediannya membeli suatu barang manakala terjadi perubahan pendapatan yang mereka peroleh; manakala terjadi perubahan harga dari barang yang bersangkutan, manakala terjadi perubahan cita rasa konsumen itu sendiri. Setiap konsumen memiliki alasan tertentu mengapa ingin membeli suatu barang kebSSutuhan atau menentukan dimana mereka akan berbelanja kebutuhan mereka.

Posisi Sungai Siak sebagai jalur perdagangan Pekanbaru, telah memegang peranan penting dalam meningkatkan pertumbuhan ekonomsi kota ini. Penemuan cadangan minyak bumi pada tahun 1939 memberi andil besar bagi perkembangan dan migrasi penduduk dari kawasan lain. Sektor perdagangan dan jasa saat ini menjadi andalan Kota Pekanbaru, yang terlihat dengan menjamurnya pembangunan ruko pada jalan-jalan utama kota ini. Selain itu, muncul beberapa pusat perbelanjaan modern, diantaranya: Plaza Senapelan, Plaza Citra, Plaza Sukaramai, Mal Pekanbaru, Mal SKA, Mal Ciputra Seraya, Lotte Mart, Metropolitan Trade Center, The Central, Ramayana dan Giant. Walau di tengah perkembangan pusat perbelanjaan modern ini, pemerintah kota terus berusaha untuk tetap menjadikan pasar tradisional yang ada dapat bertahan, di antaranya dengan melakukan peremajaan, memperbaiki infrastruktur dan fasilitas pendukungnya. Beberapa pasar tradisional yang masih berdiri, antara lain Pasar Bawah, Pasar Raya Senapelan (Pasar Kodim), Pasar Andil, Pasar Rumbai, Pasar Limapuluh dan Pasar Cik Puan (Anonim, 2013).

Tujuan dari penelitian ini adalah untuk menentukan karakteristik konsumen yang berbelanja baik dipasar tradisional maupun dipasar mderen.

\section{METODE PENELITIAN}

Penelitian ini dilaksanakan menggunakan metode survey penelitian dilaksanakan di Kecamatan Marpoyan Damai. Data diambil dengan menggunakan metode convenience sampling / accidental sampling. Dalam penelitian jumlah responden yang dijadikan sampel sebanyak 120. Data yang diperlukan dalam penelitian ini adalah data primer dan data sekunder. Dimana data primer diperoleh dari hasil wawancara dari para konsumen atau yang disebut responden dalam penelitian ini. Data tersebut diperoleh dengan cara membagikan kuisioner yang

94 Analisis Karakteristik Konsumen Yang Berbelanja Sembilan Bahan Pokok (Sembako) Di Pasar Tradisional Dan Pasar Moderen Di Kecamatan Marpoyan Damai Kota Pekanbaru 
dibagikan kepada para konsumen. Analisis yang digunakan dalam menetukan karakteristik konsumen adalah dengan analisis statistik deskriptif. Data dapat diperoleh dengan cara mewawancarai konsumen secara langsung dengan menggunakan kuisioner data yang akan diperoleh mengenai karakteristik konsumen ini adalah jenis kelamin, umur, tingkat pendidikan, jumlah tanggungan keluarga, tingkat pendapatandan lain-lain.

\section{HASIL DAN PEMBAHASAN}

\section{Karakteristik Konsumen}

Pada penelitian ini kuesioner disebar kepada rumah tangga yang ada di kelurahan Maharatu yang pada saat dilakukan penelitian berada di rumah atau bersedia memberikan jawaban untuk memilih tempat berbelanja sembako. Adapun karakteristik konsumen yang digunakan adalah: a) usia b) jenis kelamin c) suku d) pendidikan formal e) pekerjaan f) pendapatan. Konsumen yang diambil dalam penelitian ini berjumlah 120, yang mana terdapat 80 konsumen yang memilih pasar tradisional dan 40 konsumen yang memilih pasar moderen.

\section{Usia Konsumen}

Berdasarkan hasil survei diperoleh bahwa usia konsumen yang memilih pasar tradisional rata-rata berkisar antara 31 -40 tahun dengan persentase 48.75, sedangkan konsumen yang memilih pasar moderen rata-rata 21 - 30 dengan persentase 55 persen, yang berarti ada perbedaan usia juga mempengaruhi konsumen dalam pemilihan tempat belanja sembako. Hal ini dipengaruhi oleh kecendrungan dalam berbelanja yang mana semakin berumur seseorang maka lebih menyukai tempat berbelanja yang menyediakan sembako dalam bentuk segar yaitu dipasar tradisional.

Tabel 1. Karakteristik Konsumen Berdasarkan Usia

95 Analisis Karakteristik Konsumen Yang Berbelanja Sembilan Bahan Pokok (Sembako) Di Pasar Tradisional Dan Pasar Moderen Di Kecamatan Marpoyan Damai Kota Pekanbaru 


\begin{tabular}{|c|c|c|c|c|}
\hline \multirow{2}{*}{$\begin{array}{c}\text { Karakteristik } \\
\text { Konsumen }\end{array}$} & \multicolumn{2}{|c|}{ Pasar Tradisional } & \multicolumn{2}{|c|}{ Pasar Moderen } \\
\cline { 2 - 5 } & $\begin{array}{c}\text { Jumlah } \\
\text { Konsumen }\end{array}$ & $\begin{array}{c}\text { Persentase } \\
(\%)\end{array}$ & $\begin{array}{c}\text { Jumlah } \\
\text { Konsumen }\end{array}$ & Persentase (\%) \\
\hline $15-20$ tahun & 4 & 5 & 1 & 2.5 \\
\hline $21-30$ tahun & 28 & 35 & 22 & 55 \\
\hline $31-40$ tahun & 39 & 48.75 & 5 & 12.5 \\
\hline $41-45$ tahun & 5 & 6.25 & 7 & 17.5 \\
\hline$>45$ tahun & 4 & 5 & 5 & 12.5 \\
\hline Jumlah & 80 & 100 & 40 & 100 \\
\hline
\end{tabular}

\section{Jenis Kelamin}

Jenis kelamin untuk pemilihan pasar atau tempat belanja lebih dominan kaum perempuan, yang mana rata-rata jumlah konsumen untuk pasar tradisional sebanyak 54 konsumen atau sama dengan $67.5 \%$, sedangkan untuk pasar moderen yaitu sebanyak 31 konsumen atau sama dengan $77.5 \%$.

Tabel 2. Karakteristik Konsumen Berdasarkan Jenis Kelamin

\begin{tabular}{|c|c|c|c|c|}
\hline \multirow{2}{*}{$\begin{array}{c}\text { Karakteristik } \\
\text { Konsumen }\end{array}$} & \multicolumn{2}{|c|}{ Pasar Tradisional } & \multicolumn{2}{c|}{ Pasar Moderen } \\
\cline { 2 - 5 } & $\begin{array}{c}\text { Jumlah } \\
\text { Konsumen }\end{array}$ & $\begin{array}{c}\text { Persentase } \\
(\%)\end{array}$ & $\begin{array}{c}\text { Jumlah } \\
\text { Konsumen }\end{array}$ & Persentase (\%) \\
\hline Perempuan & 26 & 32.5 & 9 & 22.5 \\
\hline Laki-Laki & 54 & 67.5 & 31 & 77.5 \\
\hline Jumlah & 80 & 100 & 40 & 100 \\
\hline
\end{tabular}

\section{Suku}

Di Pekanbaru pada umumnya terdiri dari berbagai suku bangsa, ada suku melayu, minang, jawa, batak, dan tionghoa. Setelah dilakukan survei maka diketahui pula suku yang lebih banyak memilih belanja sembako ke pasar tradisional dan pasar moderen yaitu suku melayu sebanyak 33 konsumen atau $41.25 \%$, sedangkan untuk pasar moderen 17 konsumen atau $42.5 \%$. hal ini karena mayoritas suku yang ada di Kelurahan Maharatu adalah suku melayu, sehingga suku tidak mempengaruhi dalam pengambilan keputusan untuk pasar tradisional dan pasar moderen, karena bagi mereka berbelanja dimana saja sama apabila berbicara mengenai kebutuhan sembako.

\begin{tabular}{|c|c|c|}
\hline Karakteristik & Pasar Tradisional & Pasar Moderen \\
\hline
\end{tabular}




\begin{tabular}{|l|c|c|c|c|}
\hline \multicolumn{1}{|c|}{ Konsumen } & $\begin{array}{c}\text { Jumlah } \\
\text { Konsumen }\end{array}$ & Persentase (\%) & $\begin{array}{c}\text { Jumlah } \\
\text { Konsumen }\end{array}$ & $\begin{array}{c}\text { Persentase } \\
(\%)\end{array}$ \\
\hline Melayu & 33 & 41.25 & 17 & 42.5 \\
\hline Minang & 21 & 26.25 & 11 & 27.5 \\
\hline Tionghoa & 5 & 6.25 & 2 & 5 \\
\hline Batak & 10 & 12.5 & 7 & 17.5 \\
\hline Jawa & 11 & 13.75 & 3 & 7.5 \\
\hline \multicolumn{1}{|c|}{ Jumlah } & 80 & 100 & 40 & 100 \\
\hline
\end{tabular}

Tabel 3. Karakteristik Konsumen Berdasarkan Suku

\section{Pendidikan Konsumen}

Tingkat pendidikan yang dimaksud berikut ini adalah tingkat pendidikan terakhir yang ditempuh oleh konsumen. Dari hasil penelitian diperoleh tingkat pendidikan yang dominan untuk pasar tradisional yaitu rata-rata SLTA sebanyak 38 konsumen dari total 80 konsumen yang memilih atau sama dengan $47.5 \%$, sedangkan untuk pasar moderen yaitu rata-rata diploma yaitu sebanyak 13 konsumen dari total 40 yang memilih atau sama dengan $32.5 \%$. Sedikit banyaknya pendidikan juga mempengaruhi pemilihan tempat berbelanja oleh konsumen, hanya saja pada lokasi penelitian tidak terlalu dominan, sehingga konsumen masih menyukai tempat berbelanja kebutuhan sembako di pasar tradisional.

Tabel 4. Karakteristik Konsumen Berdasarkan Pendidikan

\begin{tabular}{|c|c|c|c|c|}
\hline \multirow{2}{*}{$\begin{array}{l}\text { Karakteristik } \\
\text { Konsumen }\end{array}$} & \multicolumn{2}{|c|}{ Pasar Tradisional } & \multicolumn{2}{|c|}{ Pasar Moderen } \\
\hline & $\begin{array}{c}\text { Jumlah } \\
\text { Konsumen }\end{array}$ & Persentase (\%) & $\begin{array}{c}\text { Jumlah } \\
\text { Konsumen }\end{array}$ & $\begin{array}{c}\text { Persentase } \\
(\%)\end{array}$ \\
\hline Tidak Sekolah & 0 & 0 & 0 & 0 \\
\hline Sekolah Dasar & 9 & 11.25 & 9 & 22.5 \\
\hline SLTP & 3 & 3.75 & 7 & 17.5 \\
\hline SLTA & 38 & 47.5 & 3 & 7.5 \\
\hline S-1 & 5 & 6.25 & 13 & 32.5 \\
\hline S-2 & 15 & 18.75 & 5 & 12.5 \\
\hline Jumlah & 10 & 12.5 & 3 & 7.5 \\
\hline
\end{tabular}

\section{Pekerjaan Konsumen}

Jenis pekerjaan rata-rata adalah ibu rumah tangga baik pada pasar tradisional ataupun pasar moderen sebanyak 27 konsumen memilih pasar tradisonal dan 21 pasar moderen dengan persentase masing-masing $33.75 \%$ dan $52.5 \%$. Hal ini karena ibu rumah tanggalah yang lebih berperan dalam keputusan pembelian dalam rumah tangga dan mempunyai waktu untuk berbelanja.

97 Analisis Karakteristik Konsumen Yang Berbelanja Sembilan Bahan Pokok (Sembako) Di Pasar Tradisional Dan Pasar Moderen Di Kecamatan Marpoyan Damai Kota Pekanbaru 
Tabel 5. Karakteristik Konsumen Berdasarkan Pekerjaan

\begin{tabular}{|l|c|c|c|c|}
\hline \multirow{2}{*}{$\begin{array}{c}\text { Karakteristik } \\
\text { Konsumen }\end{array}$} & \multicolumn{2}{c|}{ Pasar Tradisional } & \multicolumn{2}{c|}{ Pasar Moderen } \\
\cline { 2 - 5 } & $\begin{array}{c}\text { Jumlah } \\
\text { Konsumen }\end{array}$ & $\begin{array}{c}\text { Persentase } \\
(\%)\end{array}$ & $\begin{array}{c}\text { Jumlah } \\
\text { Konsumen }\end{array}$ & $\begin{array}{c}\text { Persentase } \\
(\%)\end{array}$ \\
\hline Ibu Rumah Tangga & 27 & 33.75 & 21 & 52.5 \\
\hline PNS & 20 & 25 & 9 & 22.5 \\
\hline Pegawai Swasta & 18 & 22.5 & 6 & 15 \\
\hline Wiraswasta & 15 & 18.75 & 4 & 10 \\
\hline \multicolumn{1}{|c|}{ Jumlah } & 80 & 100 & 40 & 100 \\
\hline
\end{tabular}

\section{Pendapatan Konsumen}

Tingkat pendapatan konsumen adalah 1.500.000- 2.999.000,mendominasi pemilihan konsumen untuk berbelanja dipasar tradisional yaitu dari total 80 konsumen yang memilih sebanyak 29 konsumen yang memilih atau sama dengan $35.25 \%$ sedangkan untuk pasar moderen dengan pendapatan 3.000.000 4.999.000 sebanyak 19 konsumen atau sama dengan $47.5 \%$ dari total 40 konsumen.

Tabel 6 : Karakteristik Konsumen Berdasarkan Pendapatan

\begin{tabular}{|l|c|c|c|c|}
\hline \multirow{2}{*}{ Karakteristik Konsumen } & \multicolumn{2}{|c|}{ Pasar Tradisional } & \multicolumn{2}{c|}{ Pasar Moderen } \\
\cline { 2 - 5 } & $\begin{array}{c}\text { Jumlah } \\
\text { Konsumen }\end{array}$ & $\begin{array}{c}\text { Persentase } \\
(\%)\end{array}$ & $\begin{array}{c}\text { Jumlah } \\
\text { Konsumen }\end{array}$ & $\begin{array}{c}\text { Persentase } \\
(\%)\end{array}$ \\
\hline$<$ Rp. 500.000 & 0 & 0 & 0 & 0 \\
\hline Rp. 500.000-1.499.00 & 12 & 15 & 3 & 7.5 \\
\hline Rp. 1.500.000-2.999.000 & 29 & 36.25 & 18 & 45 \\
\hline Rp. 3.000.000-4.999.000 & 24 & 30 & 19 & 47.5 \\
\hline$>$ Rp. 5.000.000 & 15 & 18.75 & 0 & 0 \\
\hline \multicolumn{1}{|c|}{ Jumlah } & 80 & 100 & 40 & 100 \\
\hline
\end{tabular}

\section{KESIMPULAN DAN SARAN}

\section{Kesimpulan}

Berdasarkan hasil pembahasan diatas didapatkan beberapa kesimpulan antara lain:

- Karakteristik konsumen yaitu usia konsumen yang memilih pasar tradisional 31 -40 tahun dengan persentase $48.75 \%$, konsumen yang memilih pasar moderen 21 - 30 dengan persentase 55 persen. Jenis kelamin rata-rata jumlah konsumen untuk pasar tradisional sebanyak 54 konsumen atau $67.5 \%$, pasar moderen yaitu sebanyak 31 konsumen atau $77.5 \%$, suku yang lebih banyak suku melayu sebanyak 33 konsumen atau $41.25 \%$, pasar moderen 17 konsumen atau $42.5 \%$ tingkat pendidikan yang dominan untuk pasar tradisional yaitu SLTA sebanyak 38 konsumen

98 Analisis Karakteristik Konsumen Yang Berbelanja Sembilan Bahan Pokok (Sembako) Di Pasar Tradisional Dan Pasar Moderen Di Kecamatan Marpoyan Damai Kota Pekanbaru 
atau $47.5 \%$, pasar moderen yaitu rata-rata diploma yaitu sebanyak 13 konsumen, Jenis pekerjaan adalah ibu rumah tangga baik pada pasar tradisional ataupun pasar moderen sebanyak 27 konsumen memilih pasar tradisonal dan 21 pasar moderen dengan persentase masing-masing 33.75 $\%$ dan 52.5 \%, Tingkat pendapatan konsumen adalah 1.500.0002.999.000,- mendominasi dipasar tradisional yaitu sebanyak 29 konsumen atau $35.25 \%$ pasar moderen dengan pendapatan 3.000.000 - 4.999 .000 sebanyak 19 konsumen atau $47.5 \%$.

\section{Saran}

- Untuk meningkatkan pelayanan baik kebersihan maupun akses dipasar tradisional agar diperbaiki agar konsumen yang memiliki pendapatan yang tinggi ingin berbelanja di pasar tradisional, sehingga perekonomian pedagang juga meningkat. (berdasarkan penelitian yang telah saya dilakukan sebelumnya mengenai "Analisis Kepuasan Konsumen yang Berbelanja Sembilan Bahan Pokok (Sembako) di Pasar Tradisional Dan Pasar Moderen Di Kecamatan Marpoyan Damai Kota Pekanbaru”)

\section{DAFTAR PUSTAKA}

BPS, 2013. Kota Pekanbaru Dalam Angka.http://www.bps.com.

Freddy Rangkuti, 2003, Riset Pemasaran. Cetakan Kelima. PT. Gramedia Pustaka Utama. Jakarta.

Gitosudarmo, Indriyo dan Agus Mulyono. 2001. Prinsip Dasar Manajemen. Edisi 3. Yogyakarta: BPFE.

Vermila, WM Chezy, Analisis Kepuasan Konsumen yang Berbelanja Sembilan Kebutuhan Bahan Pokok (Sembako) Pada Pasar Tradisional Dan Pasar Moderen Di Kota Pekanbaru. (Jurnal Agribisnis Vol 17 No 1). Pekanbaru. 